\title{
Desenvolvimento Regional Sustentável: indicadores e qualidade de vida no Vale do Taquari/RS
}

\section{Resumo}

Crescimento e desenvolvimento são conceitos, concepções e temas debatidos em todos os ambientes; no entanto, as percepções variam e, por vezes, são contraditórias. Atualmente se tem maior clareza de que crescimento é resultado de aspectos econômicos, e de que desenvolvimento é também resultado econômico, no entanto, inclui ainda aspectos qualitativos, avanços na qualidade de vida. Mesmo sem ter clareza do próprio conceito e das possíveis formas de mensurar o desenvolvimento, a sustentabilidade tornou-se o tema atual, um conceito amplo e com muitas variações. Apesar de expressas e propostas de forma diferente, há um consenso de que é necessária uma consciência imediata da relevância das questões ambientais no contexto do desenvolvimento. Como base nessas premissas, o objetivo do presente artigo é identificar indicadores que mensurem a qualidade de vida no Vale do Taquari. A coleta do material se deu a partir de dados bibliográficos e levantamento de indicadores de medição de qualidade de vida. Os indicadores utilizados foram PIB e PIB per capita, para determinar as condições de renda; IDESE e IDHM, buscando tratar dos temas da educação, saúde, longevidade e renda, além de informações de programas de transferência de renda, de oferta de serviços de coleta de lixo, de saneamento e abastecimento com rede de água potável, poluição das águas e do Índice do Potencial Poluidor das Indústrias para o Vale do Taquari. A partir deste conjunto de informações, identificou-se que os aspectos de renda e sociais são parcialmente atendidos, e que os aspectos ambientais, numa concepção mais atual de quais dimensões o desenvolvimento incorpora, ainda deixam a desejar e devem ser meIhor tratados pelo Vale do Taquari.

Palavras-chave: Desenvolvimento Regional Sustentável. Qualidade de vida. Vale do Taquari.

\footnotetext{
${ }^{1}$ Economista. Mestre em Ambiente e Desenvolvimento (UNIVATES), doutoranda em Desenvolvimento Regional (PPGDR/UNISC). cintia@univates.br

2 Doutor em Economia (UFRGS), docente do Programa de Pós-Graduação em Desenvolvimento Regional (PPGDR/UNISC). silvio@unisc.br
} 


\begin{abstract}
Growth and development are concepts, theories and conceptions discussed in all environments, however, the perceptions vary and are, sometimes, contradictory. Currently, it has been clearer that growth is the result of economic aspects and development is also an economic result, however, it also includes qualitative aspects, advances in quality of life. In spite of the concept itself being unclear and the possible ways of measuring development, sustainability has become the current theme, a broad concept with many variations. Although it is expressed and proposed differently, there is a consensus that it is needed an immediate awareness of the importance of environmental issues in the development context. Based on these assumptions, the aim of this article is to identify indicators that measure the quality of life in Vale do Taquari. All information gathered for this study comes from bibliographic data and surveys measuring people's quality of live. The indicators used were PIB (GDP) and PIB per capita (GDP per capita) to determine the income conditions; IDESE and IDHM, which address the issues of education, health, longevity and income, as well as information on income transfer programs, provision of waste disposal services, sewerage and supply of potable water, water pollution and the index of polluter potential of the industries in Vale do Taquari. From this set of information, it was identified that social and income aspects are partially attended and that environmental concerns, in a more current conception of what dimensions the development incorporates, are falling short and should be better treated by Vale do Taquari.
\end{abstract}

Keywords: Sustainable Regional Development. Quality of life. Taquari Valey.

\title{
1 Introdução
}

No senso comum, na mídia e mesmo no meio acadêmico, tem-se um entendimento de crescimento econômico e desenvolvimento econômico vinculados a resultados socioeconômicos. Usualmente se faz confusão entre crescimento e desenvolvimento, sendo os resultados do primeiro medidos quantitativamente, e do segundo medidos qualitativamente. $O$ que quer ser dito com essa afirmação é que, quando se fala em crescimento econômico, fala-se em resultados quantitativos da produção agregada, do consumo agregado, ou seja, do resultado matemático do crescimento contínuo da renda per capita.

Explicitando melhor, a concepção de desenvolvimento contempla, além do crescimento econômico, indicadores que demonstram melhorias das condições sociais dos indivíduos no que se refere à qualidade de vida da população, demonstrada a partir de indicadores socioeconômicos como pobreza, emprego, desigualdades sociais, de gênero e raciais; condições de saúde, alimentação, educação e moradia.

Esses são os conceitos tradicionalmente utilizados para comparações entre economias e considerados nas decisões de políticas públicas, procurando ser, de certa forma, contemplados em indicadores como Índice de Desenvolvimento Humano (IDH), Índice de Desenvolvimento Social (IDS), e outros indicadores que buscam apontar os 
resultados para "[...] uma vida longa e saudável, ser instruído, ter acesso aos recursos necessários para um nível de vida digno e ser capaz de participar da vida da comunidade" (VEIGA, 2006, p. 23).

No contexto atual, mesmo sem ter clareza do próprio conceito e das possíveis formas de mensurar o desenvolvimento, a sustentabilidade tornou-se o tema da moda: "As palavras mágicas no momento referem-se a tudo que diz respeito aos termos sustentável e sustentabilidade" (RUSCHEINSKY, 2004, p. 15). Portanto, consiste num conceito amplo e com muitas variações, que pretende atender aos mais variados objetivos, de acordo com o interesse demonstrado em cada situação.

Apesar de expressa e proposta de diferentes formas, há um consenso sobre a necessidade de uma consciência imediata da relevância das questões ambientais no contexto do desenvolvimento. Respeitar a diversidade, restringir as atividades, de acordo com a capacidade de regeneração ambiental, e contextualizar o ambiente nas proposições econômica, social e política são condições para um futuro sustentável.

O termo abre precedentes para inúmeras considerações quando não há clara definição do que se entende por 'desenvolvimento' e 'sustentável'. Alguns enfatizam que se refere a uma redundância, já que todo desenvolvimento é sustentável e não precisa deste adjetivo; outros salientam que o adjetivo serve para evidenciar uma área não abordada até fins do século XX. Alguns ainda vinculam o termo ao atendimento das necessidades das gerações atuais e futuras, mas se questiona até quais são as necessidades atuais e, ainda mais, quais serão as futuras necessidades, já que o futuro é desconhecido. Ameniza-se parcialmente essa consideração quando é aceito que não se devem saber as necessidades futuras, mas sim deixar condições ambientais, ecológicas, da biodiversidade para as futuras gerações determinarem suas próprias necessidades (BARBIERI, 1997; SACHS, 2002; 2004; MAWHINNEY, 2002).

Apesar de aceitas essas diferentes conceituações, os enfoques teóricos diferenciam-se, quando da discussão da qualidade daquilo que é sustentável, de como se dá a sustentabilidade, o atendimento das premissas do desenvolvimento sustentável ou seja, a consideração de como é viável praticar aquilo que é discutido como possível na teoria perpassa inúmeros enfoques. Alguns priorizam a ecologia, outros privilegiam a economia, outros ainda focam no cidadão ou no Estado, além daqueles que tratam da sustentabilidade a partir da interdisciplinaridade ou da racionalidade ambiental como tal. ${ }^{3}$

No entanto, quando o objetivo é mensurar o desenvolvimento sustentável, há dificuldades para medir ou avaliar parte das percepções aqui citadas. Ou seja, mensurar o desenvolvimento, conforme exposto no início deste artigo, é algo subjetivo e relativo: "Grande parte do nosso sentimento de impotência diante das dinâmicas econômicas vem do fato de que simplesmente não temos instrumentos para saber qual a contribuição das diversas atividades para o nosso bem-estar" (DOWBOR, 2007, p. 13).

Por isso, dada essa diversidade de concepções, este artigo apresenta duas vertentes do tema no pensamento econômico, a corrente dominante da Economia Ambiental e seu principal contraponto, a Economia Ecológica. A primeira corresponde à compreensão da visão tradicional de mercado, e a segunda, crítica à primeira, não se preocupa

\footnotetext{
${ }^{3}$ Entre outros autores, veja-se LEIS (1999); SOUZA (2000); CAVALCANTI ( 2001); SACHS (2002); MAY (2003); MINC (2005); LEFF (2006); MONTIBELLER-FILHO (2008); MUELLER (2012).
} 
com a mensuração ambiental do ponto de vista econômico, refutando inclusive a valoração em termos monetários, como é proposto pela corrente dominante, e reafirmando o custo ambiental do modelo atual de produção e consumo.

A partir dessas duas concepções, o plano de desenvolvimento do presente artigo contempla a discussão teórica subjacente a estes dois paradigmas, intentando identificar indicadores de desenvolvimento que mensurem a qualidade de vida no Vale do Taquari, Rio Grande do Sul. Para tanto, recorreu-se à pesquisa bibliográfica e ao levantamento de indicadores pertinentes ao objetivo, utilizando-se o PIB e o PIB per capita, para determinar as condições de renda; o IDESE e o IDHM, que abarcam educação, saúde, longevidade e renda; além de informações de programas de transferência de renda, de oferta de serviços de coleta de lixo, saneamento e abastecimento com rede de água potável, poluição das águas e do Índice do Potencial Poluidor das Indústrias para o Vale do Taquari.

Além desta seção introdutória, na sequência, são apresentadas as concepções das duas correntes teóricas em destaque, a da Economia Ambiental, na segunda seção, e a da Economia Ecológica, na terceira seção do artigo. A quarta seção discute a (im)possibilidade de valoração ambiental, conforme os pressupostos dessas duas visões teóricas, enquanto que a quinta seção apresenta os resultados encontrados no Vale do Taquari, finalizando, posteriormente, com as considerações finais.

\section{A concepção do desenvolvimento sustentável a partir da Economia Ambiental}

A Economia Ambiental é concebida a partir da visão tradicional ${ }^{4}$ do desenvolvimento ${ }^{5}$, baseada na alocação ótima dos recursos, no progresso econômico do livre mercado, produzindo mais e melhor, proporcionando esse crescimento o bem-estar social. Afirma esta visão que a preocupação com o meio ambiente deve atender às exigências do crescimento, devendo o problema ambiental ser isolado, analisado e resolvido nessas condições. A questão ambiental deve ser tratada como externa ao desenvolvimento, e não como fator que inviabiliza a produção, já que as inovações tecnológicas criariam substitutos aos recursos escassos.

O conteúdo básico da economia ambiental neoclássica, [...] compõe-se do seguinte: valoração monetária dos bens e serviços ambientais; internalização das externalidades; a proposição o poluidor paga; os direitos de propriedade; o valor econômico total dos bens e serviços ambientais; o método da valoração contingencial; a análise benefício/custo (ambiental) (MONTIBELLER-FILHO, 2008, p. 92)

As bases do capitalismo atual, segundo Hawken et al. (1999), perfazem seis con-

\footnotetext{
${ }^{4}$ Na Economia Neoclássica, segundo Souza (2000, p. 119), as “[...] questões ambientais [devem ser tratadas] dentro do rigor da racionalidade que sempre norteou as formulações da ciência econômica".

${ }^{5}$ Nesta vertente, crescimento econômico implica desenvolvimento (econômico), ou, de outra forma, são termos sinônimos. Desta forma, doravante, quando em referência a esta corrente teórica, utilizar-se-á o termo desenvolvimento, embora, nos termos da argumentação inicial, os autores não concordem com esta visão de igualdade dos conceitos.
} 
dições: (1) o progresso econômico é melhor no livre mercado; (2) as vantagens competitivas são obtidas quando as fábricas produzem mais e melhor; (3) o crescimento da produção produz o bem-estar humano; (4) a escassez de recursos estimula o desenvolvimento de substitutos; (5) as preocupações com o meio ambiente devem atender às exigências do crescimento econômico; e (6) os agentes econômicos, no mercado livre, farão a melhor alocação dos recursos.

A noção de externalidade que norteia essa concepção demonstra a falta de consideração de fatores como o meio ambiente em seus cálculos de progresso e crescimento econômico. Suas discussões centram-se na visão dos recursos escassos e nas necessidades ilimitadas, insatisfeitas do ser humano - reduzido à posição de "consumidor". Sua origem constitui-se individualista e utilitarista e "[...] considera que os recursos naturais (como fonte de insumos e como capacidade de assimilação de impactos dos ecossistemas) não representam, a longo prazo, um limite absoluto à expansão da economia" (MAY, 2003, p. 7). Neste sentido, sua crença maior é a de que a (eventual) escassez de recursos naturais levará ao incremento de seus preços, o que desencadeará um processo de inovação tecnológica com o surgimento de produtos substitutos - a crença na perfeita substituição do capital natural pelo capital construído.

A escola neoclássica baseia todas suas análises, conceitos e modelos em metodologias estáticas (de estática comparativa), na concorrência perfeita, na alocação ótima dos recursos, por parte do mercado e dos indivíduos racionais, nas externalidades ao sistema econômico e no recurso metodológico à premissa de que outros fatores permanecem constantes em seus exercícios de estática comparativa, "[...] a famosa condição ceteris paribus utilizada exaustivamente pelos economistas ortodoxos" (SEKIGUCHI; PIRES, 1995, p. 226).

A economia neoclássica, construída sobre os fundamentos do utilitarismo, individualismo metodológico e equilíbrio, define-se por uma racionalidade de maximização das utilidades individuais com a resultante determinação do uso ótimo ou eficiente dos recursos, em equilíbrio (AMAZONAS, 2002, p. 108).

E é pela eficiência na alocação dos recursos, determinada a partir da economia, que as externalidades ambientais são internalizadas no processo do desenvolvimento. A alocação ótima dos recursos, em um único equilíbrio, o do mercado, considerando a concorrência perfeita e um sistema de preços que compatibiliza com o comportamento dos agentes econômicos, que agem racionalmente em prol de si mesmos e, assim, proporcionam o crescimento material coletivo, possibilita o crescimento econômico (entendido como sinônimo do desenvolvimento).

$\mathrm{E}$, para não haver o esgotamento dos recursos naturais, a tecnologia seria eficiente para compensar o declínio desses recursos, e, quanto mais eficiente o emprego de tecnologias, maior seria a eficiência desses recursos. Assim sendo, a atividade econômica seria conduzida para uma trajetória sustentável (TOLMASQUIM, 1995).

"A abordagem de orientação econômica parece partir da premissa de que o crescimento, medido primordialmente pelo Produto Nacional Bruto, é fundamentalmente bom" (MAWHINNEY, 2002, p. 38) e constitui suas bases nas análises de demanda e oferta em uma relação às necessidades ilimitadas e recursos escassos, considerando que 
o mercado se autorregulará neste contexto. Ou seja, com o mínimo de intervenção, a considerar a teoria da demanda e oferta, o crescimento ocorrerá, pois cada um agindo em benefício próprio propiciará o benefício geral. "Na valoração de impactos de processos econômicos sobre o meio ambiente, supõe-se que, de alguma maneira, estes afetam o bem-estar (a utilidade) dos indivíduos em sociedade" (MUELLER, 2012, p. 395).

Assim, "[...] para a economia ambiental, a qualidade ambiental é considerada como um bem que proporciona utilidade aos indivíduos e, portanto, é tratado como os demais bens da economia" (SOUZA, 2000, p. 89). Os defensores desta corrente até admitem a necessidade, em alguns casos, de incorporação, em suas análises, de fatores não econômicos, mas continuam crendo que o melhor indicador de desenvolvimento econômico é o Produto Nacional Bruto.

Não obstante as críticas, a Economia Ambiental continua sendo a abordagem hegemônica no cenário internacional, e tem influenciado decisivamente as políticas ambientais contemporâneas. Ela é o fundamento teórico das abordagens de desenvolvimento sustentável baseadas no mercado, e o seu objetivo é oferecer instrumentos para corrigir as distorções de mercado e levar à maximização da eficiência econômica, considerando-se o valor econômico do meio ambiente (SOUZA, 2000, p. 118).

Em suma, para a corrente econômica tradicional, a questão da natureza trata-se de uma alocação de recursos no espaço e no tempo, considerando o consumo e investimentos dos agentes econômicos no presente, e sua racionalidade prediz que, ao buscar maior satisfação para si, o agente econômico gerará maior satisfação para o conjunto da sociedade. O Estado deveria intervir somente para corrigir falhas que ocorram neste processo de alocação dos recursos, e essas correções fariam com que o processo voltasse ao rumo de alocação eficiente dos recursos na economia.

\section{A concepção do desenvolvimento sustentável a partir da Economia Ecológica}

Já a concepção da Economia Ecológica prioriza o desenvolvimento, ao propor que a produção e o consumo considerem o meio ambiente como o fator preponderante nas suas decisões, que a regeneração e conservação dos ecossistemas sejam prioritárias em relação à produção e ao consumo da economia. Para tanto, quando falam sobre valoração ambiental, fazem-no pensando valor como importância, no sentido de dar importância aos recursos naturais, e não no sentido de precificá-los, como propõe a Economia Ambiental.

Os fundamentos desta corrente teórica estão na Conferência das Nações Unidas sobre Meio Ambiente, que ocorreu no ano de 1972, na cidade de Estocolmo. Para o grupo, as conclusões centrais perpassaram a convicção da existência de problemas ambientais globais que deveriam ser avaliados urgentemente (LEIS, 1999). Dessa forma, tornava-se necessário considerar o cenário ambiental como cenário mundial, a interdependência dos Estados, dos mercados, das populações, das ações de alguns influenciando nas reações de outros, mas as respostas para tais questões não estavam nas relações bilaterais entre países, e sim na consideração de uma perspectiva global de cooperação 
entre nações. As relações entre países ricos e pobres eram enfatizadas nestas situações. Suas análises focavam a questão populacional e o uso racional dos recursos naturais, avançando consideravelmente quando da afirmação de que a sustentabilidade é uma questão global e não local, e que as soluções também devem ser consideradas de forma global. "O eixo da conclusão de Estocolmo -72 foi a comprovação da existência de problemas ambientais globais urgentes" (LEIS, 1999, p. 149).

No ano seguinte à Conferência, o Secretário Geral Maurice Strong emprega pela primeira vez o termo ecodesenvolvimento, e este é utilizado por Ignacy Sachs para desenvolvimento de suas proposições, sendo discutido até a atualidade. Para Sachs (2002), o ecodesenvolvimento interage com vários outros aspectos, que não somente ambientais, na busca pelo verdadeiro desenvolvimento (LEIS, 1999). Suas proposições tomam formas complexas e distinguem-se por duas críticas marcantes à contemporaneidade: uma, a crítica às distinções entre o crescimento dos países desenvolvidos e subdesenvolvidos, países do Norte e Sul; e outra, a crítica ao tipo de progresso gerado pela modernização industrial.

Sachs (2002, p. 31) propõe seis aspectos que deveriam guiar o caminho do ecodesenvolvimento:

[...] a) a satisfação das necessidades básicas; b) a solidariedade com as gerações futuras; c) a participação da população envolvida; d) a preservação dos recursos naturais e do meio ambiente em geral; e) a elaboração de um sistema social garantindo emprego, segurança social e respeito a outras culturas, e f) programas de educação.

O conceito de ecodesenvolvimento de Sachs foi convertido em desenvolvimento sustentável ${ }^{6}$ por alguns teóricos da atualidade e determina um equilíbrio integrado, orgânico, de igual importância para todos os fatores.

Nessas condições, a concepção da Economia Ecológica propõe a utilização racional dos recursos naturais, a valoração dos bens naturais e a contabilidade ambiental, fundamentando o crescimento na escassez dos recursos e no atendimento das necessidades das gerações atuais e futuras. "É uma abordagem alternativa da questão econômico-ambiental e profundamente crítica à Economia Ambiental" (SOUZA, 2000 p. 141), que "defende que o sistema econômico faz parte de um sistema ecológico maior, e que o equilíbrio deste último deveria ter prioridade sobre as metas e a racionalidade econômica" (SOUZA, 2000, p. 143).

Clemente e Higachi (2000), baseados nas concepções do físico e economista Nicholas Georgescu-Roegen 7 , salientam que o circuito econômico deve levar em consideração as leis da física, como a Lei da Conservação da Matéria, pela qual as atividades de produção apenas transformam matéria, não criam e nem destroem, bem como a primei-

\footnotetext{
${ }^{6}$ Ressalte-se também que o termo 'desenvolvimento sustentável' foi apropriado pelo mainstream econômico, mas, embora apresentado em termos sedutores, na verdade, representa a noção de submissão e apropriação do meio ambiente para as necessidades de manutenção do volume de produção atual e reprodução do capital.

7 Para Georgescu-Roegen, "[...] o destino do homem é o de ter uma vida curta, mas fogosa, em vez de uma existência longa, mas vegetativa, sem grandes eventos. De forma bem irônica, sugere que deixemos a outras espécies - as amebas, por exemplo, que não têm ambições espirituais -herdar o globo terrestre ainda abundantemente banhado pela luz solar" (apud VEIGA, 2006, p. 85).
} 
ra e a segunda leis da Termodinâmica, enfatizando a primeira que há a impossibilidade de criação ou destruição da energia, e a segunda, que a entropia é crescente, pois os processos químicos e físicos resultam da transformação de outras formas de energia em calor, ou seja, a atividade econômica apenas transforma energia de um estado de disponibilidade para um estado latente, de indisponibilidade. Por esta concepção, a interação do meio ambiente com a atividade econômica deve considerar os fatores ambientais e mensurá-los no processo de desenvolvimento econômico.

Conforme May (1995), para que a economia possa ser sustentável, é necessário que todas as decisões políticas considerem o uso adequado dos recursos naturais, uso adequado aqui considerado como aqueles recursos valorados e explorados dentro de uma condição de preservação e regeneração de ecossistemas. Bartelmus (1993, p. 157) apoia essa concepção quando afirma:

O desenvolvimento sustentável tem como finalidade a integração de preocupações ambientais ao bojo das políticas socioeconômicas, fazendo estas políticas responsáveis por seus impactos ambientais. Assim, contabilizar tanto a degradação e a exaustão ambientais como o desempenho econômico é um primeiro passo no sentido dessa integração.

A economia tradicional tratou historicamente o meio ambiente como fonte inesgotável de recursos e sempre considerou a produção de forma isolada dos aspectos sociais, políticos, ambientais, éticos. Agora, "[...] o sentimento é de que haja necessidade de uma mudança de rumo no desenvolvimento econômico, o que irá requerer uma 'virada paradigmática'” (MAY, 1995, p. 239). Nem a ecologia pura nem a teoria neoclássica são possíveis para tratar deste tema. Os fundamentos passam por uma nova forma de preconizar o desenvolvimento, a qual considere o crescimento fundamentado na escassez dos recursos naturais e no atendimento das necessidades das gerações atuais e futuras, em que o progresso tecnológico seja um aliado forte.

A análise da Economia Ecológica inicia pelo meio ambiente e integra a economia, diferentemente da Economia Neoclássica, que verifica a eficiência da economia e considera a natureza como externalidade, integrada ao processo quando necessária à sua análise. São necessárias a estimação dos limites do ecossistema (capacidade de suporte) e a valoração dos bens naturais, perpassando pelos custos e benefícios do uso de energia, da biodiversidade, da natureza em geral. Assim, os economistas desta linha podem construir cenários alternativos para uso racional dos recursos ambientais, tanto em projetos econômicos como em projetos políticos nacionais e internacionais.

May (1995) enfatiza que existem duas formas para que a relação ambiente e economia seja eficaz: numa, a análise custo-benefício das atividades econômicas iria ocorrer em função dos fatores ambientais; noutra, imaginando a primeira não ser suficiente e efetiva, a análise determinaria limites para as atividades econômicas em função da natureza. $\mathrm{O}$ autor destaca que qualquer método para possibilitar uma economia ecológica depende "[...] muito da própria percepção do que exatamente implica a sustentabilidade para a manutenção do estoque dos recursos naturais" (MAY, 1995, p. 245).

A corrente da Economia Ecológica faz frente à concepção da Economia Ambiental e tem maior dificuldade de valorar os aspectos defendidos por esta última como primordiais para análise e busca do desenvolvimento sustentável, pois que entende que a 
valoração é uma concepção subjetiva e individual, e não sujeita ao mecanismo de preços tal como apregoado pela Economia Ambiental.

\section{A valoração ambiental na Economia Ambiental e na Economia Ecológica}

Já foi aqui explicitada a dificuldade de valorar aspectos que determinem o desenvolvimento sustentável; no entanto, nessa tentativa

[...] pode-se dizer que o valor é uma grandeza que qualifica um objeto e que é responsável por orientar a decisão/ação do sujeito sobre ele. $O$ valor é atribuído, portanto, ao objeto, mas ele somente assume essa grandeza quando este objeto é alvo de uma decisão/ação por parte de um sujeito (SOUZA, 2000, p. 176).

Quando analisamos a Economia Ambiental, o modelo de valoração baseado nas preferências individuais é complementado com as medições das externalidades, que "[...] avaliam em geral o efeito do meio ambiente e das suas alterações: (a) sobre a produção [...]; (b) sobre o próprio custo [...]; e sobre o bem-estar individual [...]", ou seja, utiliza as "[...] referências do próprio mercado, ou tenta simulá-lo" (SOUZA, 2000, p. 115). Para Mueller (2012, p. 396), "[...] na valoração de custos e benefícios ambientais decorrentes do funcionamento do sistema econômico, o procedimento usual é, sempre que possível, empregar preços de mercado". Portanto, a referência primordial para a Economia Ambiental são os próprios preços de mercado dos bens em produção no sistema - preços estes, diga-se de passagem, 'errados' pois que não incorporam as externalidades como a própria vertente reconhece.

Comune $(1993$, p. 49) enfatiza que a “[...] economia neoclássica do bem-estar desenvolveu o conceito de economias externas ou externalidades para tratar com as questões dos custos sociais, conceito este que, com refinamentos, serve de linha básica nas análises sobre o assunto".

Assim, a fonte de valor para o meio ambiente, segundo a concepção da Economia Ambiental, é que este possui utilidade para a sociedade atual, devendo haver essa mesma disponibilidade também no futuro (com o mesmo intento de proporcionar utilidade às gerações futuras). Esta corrente reconhece ainda que há um "[...] valor de existência do meio ambiente" (SOUZA, 2000, p. 181), pelo qual se deve atribuir valor para espécies em extinção, ambientes sujeitos à perda de biodiversidade, entre outros, porém sempre primando pela valoração via preferências estabelecidas de acordo com os parâmetros de utilidade dos indivíduos (consumidores) e os preços de mercado.

A Economia Ambiental considera como princípio que "[...] a eficiência econômica é atingida na posição de equilíbrio geral, as decisões de alocação de recursos, desde que considerem o valor total daqueles usados na produção, serão mais eficientes" (MONTIBELLER-FILHO, 2008, p. 93).

Para compatibilizar meio ambiente e economia, valorando os recursos naturais no plano econômico, Bartelmus (1993, p. 157) reafirma a necessidade de uma "[...] contabilidade integrada [que] permite a definição rigorosa dos indicadores econômicos ajustados ao meio ambiente, como produto interno, renda nacional, capital e forma- 
ção de capital; consumo e valor adicionado". Mas, como a atribuição de valores pode ser limitada em alguns casos, principalmente se estão implícitos critérios qualitativos, a avaliação social deverá ser considerada como forma efetiva da valoração da natureza.

Young (2003) reafirma a proposição de Bartelmus (2003) quando propõe não somente a valoração dos bens naturais, mas também a inclusão destes na contabilidade nacional. Para o autor, "[...] o grande desafio é conseguir conciliar ambas em uma estrutura comum, flexível o suficiente para manter a coerência interna das contas nacionais e introduzir adequadamente o problema dos recursos naturais" (YOUNG, 2003, p. 129). Outro autor que trata da contabilidade verde é Serafy (2001), que também propõe que as contas nacionais contenham indicadores naturais e que, dessa forma, sejam utilizadas nas decisões políticas.

Considerando que "[...] o valor econômico de um bem ambiental surge em função de três tipos de preferência de uma pessoa: pelo uso efetivo do objeto; pelo uso opcional por ela mesma ou por outras pessoas no futuro; e pela preferência à existência do bem ou objeto" (MONTIBELLER-FILHO, 2008, p. 111), várias metodologias e ferramentas são propostas para calcular essas externalidades e modelar a Economia Ambiental.

Enfim, para tal corrente, todos os indivíduos, agindo racionalmente e em prol de si mesmos, neste mercado perfeito, terão como resultado de sua ação o melhor para o coletivo. Os problemas ambientais serão externalidades e, como tais, serão percebidos como resultado de inadequações da natureza, e não como insuficiência do mercado.

Já para a Economia Ecológica

[...] a fonte ou origem do valor, já que acreditam que o meio ambiente possui apenas um valor intrínseco, é o próprio ecossistema (o próprio meio ambiente), enquanto que o objetivo da decisão/ação racional a que este valor conduz é o de manter o equilíbrio ecológico dos ecossistemas em geral, minimizando os riscos e as alterações promovidas pelas atividades humanas a eles (SOUZA, 2000, p. 200)

Constanza (1993, p. 121) propõe uma agenda para a sustentabilidade com vistas à manutenção do sistema de sustentação da vida na Terra, avaliação do que chama de "serviços do ecossistema e do capital natural", uma contabilidade de um novo sistema que leva em conta economia e ecologia, modelos econômico-ecológicos para diferentes escalas geográficas de desenvolvimento, instrumentos para gerenciamento ambiental e manutenção do capital natural, aspectos que considera básicos para uma sustentabilidade do desenvolvimento. Define, assim, uma possível interpretação para a sustentabilidade a partir da quantidade de consumo que poderá existir, sem degradar os estoques de capital, inclusive o capital natural, considerado a partir de tudo que compõe o solo e a atmosfera, biomassa, espécies de animais, formadores dos ecossistemas. Portanto, a produção deveria limitar-se considerando a renovação e conservação do capital natural a partir dos requisitos de manutenção da biodiversidade dos ecossistemas.

Para tanto, Constanza (1993) afirma que a sustentabilidade do desenvolvimento somente será possível se houver objetivos locais e de curto prazo que atendam às necessidades atuais e futuras. Nessas condições, é necessário determinar alguns critérios: 
[...] a) estabelecer uma hierarquia de objetivos para o gerenciamento e o planejamento econômico e ecológico a nível local, nacional e global; b) desenvolver melhores capacidades de modelagem ecológica econômica regional e global, de forma a permitir uma visão da gama de possíveis consequências de nossas atividades atuais; c) ajustar preços e outros incentivos locais para que reflitam os custos ecológicos globais a longo prazo, inclusive a incerteza; e d) desenvolver programas que não levem ao declínio contínuo do estoque de capital natural (CONSTANZA, 1993, p. 112).

Ortiz (2003, p. 81), considerando que "todo recurso ambiental tem um valor intrínseco", busca valorar os bens naturais segundo uma condição de equivalência com outros bens na economia em sua contribuição para o bem-estar social. Essa valoração não é voltada para a análise dos recursos ambientais, e sim para as preferências da sociedade com relação aos recursos que estão disponíveis.

Também Norgaard (2001, p. 91) propõe a valoração ambiental, mas enfatiza que ela só é possível se forem consideradas as dimensões moral e política, pois sustenta que "a sustentabilidade é, em última instância, um problema distributivo, e não uma questão de elevação de eficiência". Ou seja, de nada adianta calcular o valor dos bens naturais sem considerar seu uso e sua distribuição social, tendo como base a mediação política e a fundamentação moral de responsabilidade para com os outros.

Um dos pressupostos para a Economia Ecológica, segundo Hawken et al. (1999), ultrapassa o aceite de que o meio ambiente é um fator que baseia o conjunto da economia e não somente mais um dos fatores que deve estar atrelado ao sistema econômico, e, para tanto, as escolhas dos agentes econômicos devem perceber tal contexto, "escoIhas melhores, um meio ambiente melhor, comunidades mais seguras, empregos que sustentam a família, mais segurança econômica, maior apoio à família, impostos mais baixos, governos mais eficazes e mais controle local" (HAWKEN et al., 1999, p. 302).

Daly (2001, p. 180) avança significativamente na concepção da Economia Ecológica, enfatizando que "a economia é um subsistema do meio ambiente e depende dele tanto como fonte de insumos de materiais como depósito para o lançamento da produção de lixo". Essa é uma afirmação que inverte a concepção inicial de que a natureza é parte do contexto econômico e cria total dependência do progresso econômico, da produção e consumo, a partir dos recursos naturais. Ao contrário, indica que, sem estes, a produção não pode ocorrer, e o consumo não irá se efetivar.

Conforme May (1995), para que a economia possa ser sustentável, é necessário que todas as decisões políticas considerem o uso adequado dos recursos naturais, uso adequado aqui considerado como aqueles recursos valorizados e explorados dentro de uma condição de preservação e regeneração de ecossistemas.

A corrente que trata da questão da sustentabilidade a partir de uma economia ecológica traz a discussão, como um problema de alocação de recursos naturais, ao longo do tempo, considerando sua finitude, o que determina que haja limites para seu uso. Para tanto, propõe formas e contextos de monitoramento, valoração e determinação do melhor uso dos recursos naturais, considerando o desenvolvimento socioeconômico. Suas concepções perpassam incertezas e riscos intrínsecos ao desenvolvimento e considera, em sua análise, as dimensões culturais e éticas para a tomada de decisões. 
Mas as análises de valoração ambiental são análises de curto prazo, pois, no longo prazo, as incertezas podem distorcer os resultados, considerando preferências e recursos equivalentes. A valoração dos recursos naturais pode ajudar nas decisões das políticas públicas orientadas para a preservação e até conservação de recursos naturais, no entanto, valorar algo comparativamente a outros bens sempre tem riscos de análise, e não há como valorar espécies ainda desconhecidas e que podem ser perdidas em uma análise parcial ou falha de valoração ambiental.

As dificuldades da concepção a partir da Economia Ecológica estão na pouca disponibilidade de dados estatísticos sobre os recursos naturais, nas dificuldades já expostas para valoração desses recursos e nas incertezas quanto ao futuro, que impossibilitam o atendimento do conceito básico de sustentabilidade, de atendimento às necessidades das atuais e futuras gerações.

\section{Indicadores do desenvolvimento regional sustentável}

Tendo clareza das dificuldades de mensurar o meio ambiente e aceitando que a Economia Ecológica aproxima mais a realidade das percepções teóricas do desenvolvimento sustentável aqui aceitas, vamos inferir sobre uma possível sustentabilidade regional a partir dos indicadores atualmente existentes.

Nessas condições, estamos considerando enquanto região o Vale do Taquari,

[...] uma região composta atualmente por 36 municípios, segundo a área de abrangência dos COREDES - Conselhos Regionais de Desenvolvimento do Estado do Rio Grande do Sul. Localiza-se na região central do Rio Grande do Sul e dista em média 150 quilômetros de Porto Alegre, integrando a 'região funcional 2', juntamente com o COREDE Vale do Rio Pardo (CODEVAT, 2009, p. 16).

O Vale do Taquari possui 1,71\% da área total do Estado e, em 2011, foi responsável por 3,23\% do PIB gaúcho, concentrando ainda 3,07\% da população do Rio Grande do Sul. A região é responsável por 30\% da produção de frangos, $15 \%$ da produção de suínos e $9 \%$ da produção leiteira estadual (FEE, 2014). Parcela significativa do setor industrial está vinculada ao agronegócio e à produção de alimentos, destacando-se também na produção de móveis e confecções, entre outros.

Se utilizados os preceitos da Economia Ambiental, cujos resultados têm como melhores indicadores os indicadores de PIB e PIB per capita, demonstrados na Tabela 1, pode-se inferir que, no Vale do Taquari, nesta última década, os resultados foram satisfatórios, crescendo continuamente e sendo compatíveis com a média estadual. Ou seja, considerando estes indicadores, essa é uma região próspera nos termos defendidos por Rattner (1994). 
Tabela 1 - PIB e PIB per capita, Vale do Taquari e RS - 2000, 2005, 2010 e 2011

\begin{tabular}{ccrrrr}
\hline \multicolumn{2}{c}{ Indicador } & \multicolumn{1}{c}{$\mathbf{2 0 0 0}$} & \multicolumn{1}{c}{$\mathbf{2 0 0 5}$} & \multicolumn{1}{c}{$\mathbf{2 0 1 0}$} & \multicolumn{1}{c}{$\mathbf{2 0 1 1}$} \\
\hline & Vale do Taquari & 2.667 .993 & 4.496 .783 & 7.739 .330 & 8.510 .190 \\
PIB & RS & 81.814 .714 & 144.218 .198 & 252.482 .597 & 263.633 .398 \\
(R\$ mil) & VT / RS & $3,26 \%$ & $3,12 \%$ & $3,07 \%$ & $3,23 \%$ \\
& Vale do Taquari & 8.290 & 13.916 & 23.608 & 25.798 \\
PIB per capita & RS & 7.978 & 13.298 & 23.606 & n. d. \\
(R\$) & VT / RS & $103,91 \%$ & $104,65 \%$ & $100,01 \%$ & - \\
\hline
\end{tabular}

Fonte: elaborado pelos autores, a partir de FEE (2014).

No entanto, à medida que agregamos outros indicadores, o quadro começa a se alterar. Incluindo indicadores conhecidos do desenvolvimento, que medem as condições de saúde, educação e renda, o Vale do Taquari ainda se destaca entre as regiões mais desenvolvidas: os indicadores Índice de Desenvolvimento Sócio Econômico (IDESE) e Índice de Desenvolvimento Humano Municipal (IDHM) são de 0,765 e 0,727, respectivamente, para o ano de 2010 (FEE, 2014; IBGE, 2014), o que coloca a região numa condição de médio desenvolvimento apenas (valores superiores a 0,8 são considerados de alto desenvolvimento).

Na Tabela 2, são apresentadas as informações abertas dos blocos educação, saúde e renda, no caso do IDESE, e educação, longevidade e renda no caso do IDHM. Desagregando os indicadores, verificam-se, em algumas dimensões, resultados que colocam o Vale do Taquari com indicadores melhores ou muito próximos da média estadual e, em alguns deles, com classificação de 'alto nível de desenvolvimento', como no caso da saúde, para o IDESE, e a longevidade para o IDH - longevidade que é uma proxy de saúde, pois que se entende-que sem saúde não há condições de alcançar uma vida longeva.

Tabela 2 - IDESE e IDHM, Vale do Taquari e Rio Grande do Sul, 2010

\begin{tabular}{lcc}
\hline Indicador & Vale do Taquari & RS \\
\hline IDESE - Índice de Desenvolvimento Socioeconômico & 0,765 & 0,727 \\
IDESE Educação & 0,728 & 0,654 \\
IDESE Saúde & 0,848 & 0,803 \\
IDESE Renda & 0,717 & 0,724 \\
IDHM - Índice de Desenvolvimento Humano Municipal & 0,727 & 0,746 \\
IDHM Educação & 0,607 & 0,642 \\
IDHM Longevidade & 0,851 & 0,840 \\
IDHM Renda & 0,748 & 0,769 \\
\hline
\end{tabular}

Fonte: elaborado pelos autores, a partir de FEE (2014) e IBGE (2014).

Já na Tabela 3, são apresentadas as informações acerca do Programa Bolsa Família, programa de transferência de renda do Governo Federal que atende famílias com 
rendimento per capita mensal abaixo de $\mathrm{R} \$ 70,00$, consideradas extremamente pobres, e até $\mathrm{R} \$ 140,00$ per capita, consideradas pobres. Assim, observando os dados a partir deste indicador, no Vale do Taquari são atendidas menos de 7.000 famílias, o que, se considerarmos o número de domicílios (112.127, conforme o Censo Demográfico 2010 do IBGE), é pouco mais de $6 \%$ dos domicílios que recebe esse benefício. Nas mesmas condições, no Estado, esse percentual é de quase $13 \%$. Assim, pode-se inferir que o Vale do Taquari, comparativamente à média estadual, possui metade do percentual estadual de moradores com necessidade de transferência de renda.

\section{Tabela 3 - Beneficiários do Programa Bolsa Família, Vale do Taquari e} Rio Grande do Sul, 2008 - 2012

\begin{tabular}{lrrrrr}
\hline Abrangência/Ano & $\mathbf{2 0 0 8}$ & $\mathbf{2 0 0 9}$ & $\mathbf{2 0 1 0}$ & $\mathbf{2 0 1 1}$ & $\mathbf{2 0 1 2}$ \\
\hline Vale do Taquari & 5.757 & 6.608 & 6.763 & 6.475 & 6.854 \\
Rio Grande do Sul & 367.631 & 462.966 & 453.761 & 450.778 & 463.519 \\
VT / RS & $1,57 \%$ & $1,43 \%$ & $1,49 \%$ & $1,44 \%$ & $1,48 \%$ \\
\hline
\end{tabular}

Fonte: elaborado pelos autores a partir de IPEA (2014).

Os indicadores anteriormente referidos avançam para determinar condições de qualidade de vida das sociedades, mas ainda não dão conta de medir o desenvolvimento sustentável, segundo as correntes de pensamento da Economia Ecológica, pois valorizam sobremaneira os aspectos econômicos, os quais se entende são vinculados mais à concepção de crescimento que propriamente à de desenvolvimento.

Considerando a disponibilidade de dados municipais ou regionais, pode-se incluir informações acerca do saneamento básico, que amplia a visão e a relação sociedade e meio ambiente. Em se tratando de abastecimento de água potável, a região tem $15 \%$ da população não atendida pela rede geral de água potável, ou seja, são 16.496 domicílios que se utilizam de poço ou nascente para abastecimento de água.

Praticamente $93 \%$ do lixo gerado nos municípios é coletado, o restante é jogado, enterrado ou queimado. No entanto, estes $93 \%$ que são coletados, em sua grande maioria, são destinados para o aterro sanitário do município de Minas do Leão, sem nenhum tipo de separação e/ou reutilização do reciclável.

Em se tratando de esgotamento, somente $11 \%$ dos domicílios da região estão ligados à rede geral de esgoto, a maioria (57\%) possui fossa séptica, $30 \%$ possuem fossa rudimentar e aproximadamente $5 \%$ dos domicílios não possuem banheiro, ou se utilizam de vala para a destinação dos dejetos (FEE, 2014; CODEVAT, 2014). Como resultado, nas dimensões coleta de lixo e abastecimento de água potável, os indicadores da região situam-na num patamar de alto desenvolvimento; no entanto, mesmo assim, indicam que parcela importante da população não tem acesso adequado a esses serviços, que contribuem sobremaneira para uma qualidade de vida digna, especialmente no tocante à questão do esgotamento sanitário. Neste sentido, há muito ainda que avançar, considerando que o patamar adequado é de $100 \%$ de cobertura dos serviços de abastecimento de água potável, rede de coleta do esgoto sanitário e coleta de lixo, com separação de orgânicos e recicláveis, e correta destinação desse tipo de lixo. 
Tabela 4 - Indicadores de saneamento, Vale do Taquari e Rio Grande do Sul, 2010

\begin{tabular}{lcc}
\hline Indicador (percentual sobre total de domicílios) & Vale do Taquari & RS \\
\hline Esgotamento - rede geral & 0,107 & 0,481 \\
Lixo coletado & 0,927 & 0,921 \\
Abastecimento de água - rede geral & 0,850 & 0,853 \\
\hline
\end{tabular}

Fonte: elaborado pelos autores a partir de FEE (2014).

Ainda, para não tratar somente do saneamento nas áreas urbanas, no meio rural, há uma concentração elevada na criação de animais, conforme exposto anteriormente na caracterização da produção da região, e com baixa adequação para o correto manejo e possível reutilização dos dejetos orgânicos. O tema aqui levantado é tão saliente que foi diagnosticado no Plano da Bacia Hidrográfica Taquari-Antas, já que 35\% das doenças de veiculação hídrica do Estado do RS ocorrem nesta bacia. Também, segundo o Plano, todos os pontos analisados neste trecho da bacia resultaram em classes de água 3 ou 4, considerando Resolução do CONAMA ${ }^{8}$ - Conselho Nacional de Meio Ambiente (SEMA, 2012).

Representando graficamente, em formato de radar tais informações, percebemos que as condições de educação, saúde e renda demonstram condições de medianas à alta; no entanto, os impactos no ambiente, no que tange às questões de saneamento, demonstram que há uma distância significativa entre os indicadores ideais e os resultados demonstrados aqui. Não foram demonstrados graficamente, mas devem ainda ser considerados os fatores citados, quando dos resultados de análises de água na bacia hidrográfica da qual essa região faz parte.

\section{Gráfico 1 - Indicadores de Desenvolvimento do Vale do Taquari, 2010}

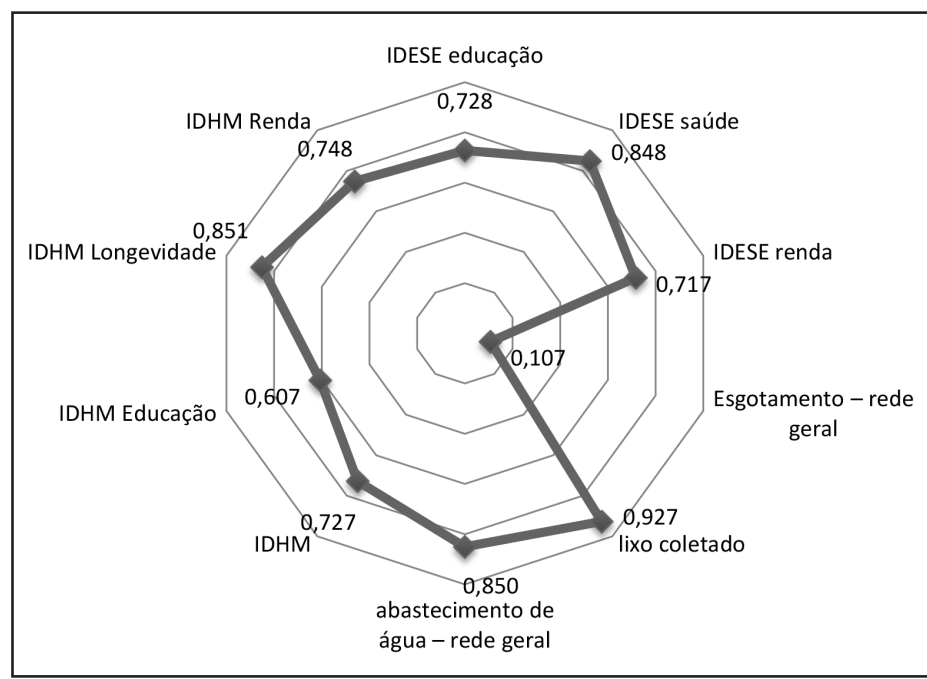

Fonte: elaborado pelos autores.

\footnotetext{
${ }^{8}$ O CONAMA determina as classes de água, avaliadas de 1 a 4, da melhor para a pior qualidade (Resolução 357/2005).
} 
Por fim, ainda considerando a disponibilidade de informações regionais, apresenta-se o Índice de Potencial Poluidor da Indústria (Inpp-I) ${ }^{9}$, calculado pela Fundação de Economia e Estatística (FEE). Os últimos dados disponíveis são do ano de 2009 e seguem na Tabela 5, inserida na próxima página.

Neste indicador, o Vale do Taquari é a sexta região em termos de potencial poluidor da indústria. Se considerarmos que possui menos de $2 \%$ da área e em torno de $3 \%$ da população do Estado, é significativo ter um potencial poluidor acima de três pontos percentuais, o que indica uma concentração de atividades industriais com potencial poluidor superior ao da participação da região nos outros dois indicadores - infere-se que, proporcionalmente, as indústrias da região têm um potencial poluidor superior ao das demais localizadas nas outras regiões.

Considerando o exposto até o presente momento, a partir dos dados disponíveis, verifica-se que o Vale do Taquari possui renda e condições de educação e saúde no mesmo grau de igualdade ou até melhores que a média estadual, e, ainda, quando avaliado a partir das necessidades de programas sociais, estas são menores que as da média estadual, o que indica um 'bom' desempenho do ponto de vista de indicadores tradicionais de desenvolvimento, tratado como sinônimo de crescimento econômico e produção material - de bens e serviços comercializados no mercado.

No entanto, quando avaliados os dados de potencial poluidor, da disponibilidade de serviços de saneamento básico e de poluição dos rios, os resultados deixam de ser positivos e demonstram que os aspectos ambientais não estão sendo atendidos nas mesmas condições que os aspectos econômicos e sociais. Assim, não é possível, em nível regional, configurar uma situação de desenvolvimento sustentável, ou seja, a sustentabilidade, a partir da percepção de que ela implica a harmonia entre homem e natureza e o atendimento simultâneo dos "critérios de relevância social, prudência ecológica e viabilidade econômica, os três pilares do desenvolvimento sustentável" (SACHS, 2002, p. 35).

Considerando as informações disponíveis até o momento, não é possível afirmar que a região apresenta uma solidariedade com as gerações atuais, de forma simultânea e homogênea, e com as gerações futuras, de forma que possibilite substituição e atendimento das necessidades ao longo do tempo.

\footnotetext{
9 "Em sendo sintético, o número deve abarcar tanto a intensidade do potencial de poluição das atividades econômicas desenvolvidas [indústrias extrativas e de transformação], quanto o patamar produtivo, que traz a contribuição ao potencial poluidor total" (FEE, 2014, p. 1).
} 
Tabela 5 - Índice de Potencial Poluidor da Indústria (Inpp-I) e sua participação em relação ao Estado, 2009

\begin{tabular}{|c|c|c|}
\hline COREDE & INPP-I & PARTICIPAÇÃO COREDE (\%) \\
\hline Total do Rio Grande do Sul & 87,7393 & 100,00 \\
\hline Metropolitano do Delta do Jacuí & 23,3721 & 26,64 \\
\hline Vale do Rio dos Sinos & 20,4240 & 23,28 \\
\hline Serra & 14,7187 & 16,78 \\
\hline Sul & 4,7209 & 5,38 \\
\hline Vale do Rio Pardo & 4,1530 & 4,73 \\
\hline Vale do Taquari & 3,1928 & 3,64 \\
\hline Produção & 2,3110 & 2,63 \\
\hline Vale do Caí & 1,6556 & 1,89 \\
\hline Norte & 1,5739 & 1,79 \\
\hline Paranhana Encosta da Serra & 1,4521 & 1,66 \\
\hline Centro Sul & 1,3603 & 1,55 \\
\hline Fronteira Noroeste & 1,2514 & 1,43 \\
\hline Fronteira Oeste & 1,2205 & 1,39 \\
\hline Alto Jacuí & 0,8701 & 0,99 \\
\hline Missões & 0,8273 & 0,94 \\
\hline Noroeste Colonial & 0,6587 & 0,75 \\
\hline Central & 0,5363 & 0,61 \\
\hline Jacuí Centro & 0,5222 & 0,60 \\
\hline Campanha & 0,5101 & 0,58 \\
\hline Hortênsias & 0,5007 & 0,57 \\
\hline Nordeste & 0,4694 & 0,54 \\
\hline Médio Alto Uruguai & 0,3177 & 0,36 \\
\hline Rio da Várzea & 0,2885 & 0,33 \\
\hline Campos de Cima da Serra & 0,2578 & 0,29 \\
\hline Celeiro & 0,2192 & 0,25 \\
\hline Litoral & 0,1491 & 0,17 \\
\hline Alto da Serra do Botucaraí & 0,1147 & 0,13 \\
\hline Vale do Jaguarí & 0,0911 & 0,10 \\
\hline
\end{tabular}

Fonte: FEE (2014). 


\section{Considerações finais}

A avaliação da discussão sobre desenvolvimento e sustentabilidade revela que os dados e indicadores utilizados mundialmente para determinar se países são desenvolvidos ou subdesenvolvidos são insuficientes, pois não consideram todos os aspectos a serem avaliados no desenvolvimento. $E$ mais, se é aceito que desenvolvimento é uma relação de igualdade, equidade e solidariedade, não se tem condições, atualmente, de afirmar quais são os países ou regiões desenvolvidas, já que essas dimensões não são medidas de forma plena.

Considerando a disponibilidade de informações atuais, IDESE e IDHM dão conta de medir aspectos de educação, saúde e renda. No caso da renda, as informações são contempladas também nos indicadores formais tradicionais do PIB e PIB per capita. Quando incluídas informações dos programas de transferência de renda, esses indicadores dão conta, mesmo que minimamente, de avaliar as condições de cada município e/ou região, possibilitando efetuar um comparativo entre regiões. Mas, mesmo estes indicadores deixam de lado aspectos que distorcem o indicador de renda, como, por exemplo, a produção para autoconsumo. São estes os indicadores que hoje possuem metodologia internacional, com exceção do IDESE, aceitos por todos e que trazem informações relevantes, para a mediação da qualidade de vida - no marco da lógica tradicional de crescimento econômico - e que, dessa forma, permitem comparações entre regiões/países, pois que utilizam o mesmo procedimento metodológico.

Agora, considerando as informações disponíveis municipalmente, avançamos para aspectos da concepção de desenvolvimento sustentável, a partir da Economia Ecológica, mesmo que de forma superficial ou transversal, como são as medições de coleta de lixo, de saneamento e de abastecimento com rede de água. Quando avaliados também os aspectos de poluição das águas e do índice poluidor das indústrias, esses indicadores se aproximam de ações que possibilitam minimizar a degradação do ambiente, a interferência antrópica no meio ambiente e os seus efeitos nas sociedades. Nessas condições, os dados mais significativos, no Vale do Taquari, são os vinculados ao esgotamento e à disponibilidade de rede de água tratada, ao potencial poluidor da indústria, os quais trazem informações, mesmo que superficialmente, que devem ser mais bem avaliadas e tratadas por esta região.

Em suma, quando avaliados os aspectos da Economia Ambiental e da Economia Ecológica, tem-se que os aspectos de renda são atendidos, os aspectos sociais parcialmente atendidos, e que os aspectos ambientais devem ser melhor tratados pelo Vale do Taquari. Considerar, portanto, as condições de equidade na sociedade e de solidariedade com as atuais e futuras gerações, aproxima-se de uma condição de desenvolvimento e sustentabilidade próprios dos pressupostos da Economia Ecológica. No entanto, considerar principalmente (ou somente!) a liberdade de escolha dos indivíduos como critério fundamental, não permite se alcançar uma condição de 'verdadeiro' desenvolvimento sustentável. 


\section{Referências}

AMAZONAS, M. de C. Desenvolvimento sustentável e teoria econômica: o debate conceitual nas perspectivas neoclássica, institucionalista e da economia ecológica. In: NOBRE, M.; AMAZONAS, M. de C. (Orgs.). Desenvolvimento sustentável: a institucionalização de um conceito. Parte II. Brasília: IBAMA, 2002. p. 107-279.

BARBIERI, J. C. Desenvolvimento e meio ambiente: as estratégias de mudanças da agenda 21. Petrópolis: Vozes, 1997.

BARTELMUS, P. A contabilidade verde para o desenvolvimento sustentável. In: MAY, P. H.; MOTTA, R. S. da (Orgs.). Valorando a natureza: análise econômica para o desenvolvimento sustentável. Rio de Janeiro: Campus, 1993. p. 157-104.

CAVALCANTI, C. (Org.). Meio ambiente, desenvolvimento sustentável e políticas públicas. São Paulo: Cortez, 2001.

CLEMENTE, A.; HIGACHI, H. Y. Economia e Desenvolvimento Regional. São Paulo: Atlas, 2000.

CODEVAT. Conselho de Desenvolvimento do Vale do Taquari. Disponível em: <http://www.codevat.org.br/site/home>. Acesso em: 14 jun. 2014.

. Planejamento Estratégico Regional do Vale do Taquari. Lajeado: CODEVAT, 2009. Disponível em: <http://www.codevat.org.br/site/home/pagina/id/51/? Planejamento-Estrategico-Regional-2009-2010.html>. Acesso em: 14 jun. 2014.

COMUNE, A. E. Meio ambiente, economia e economistas. In: MAY, P. H.; MOTTA, R. S. da (Orgs.). Valorando a natureza: análise econômica para o desenvolvimento sustentável. Rio de Janeiro: Campus, 1993. p. 45-58.

CONSTANZA, R. Developing ecological research that is relevant achieving sustainability. In: Ecological Applications, 1993

DALY, H. E. Políticas para o desenvolvimento sustentável. In: CAVALCANTI, C. (Org.). Meio ambiente, desenvolvimento sustentável e políticas públicas. São Paulo: Cortez, 2001. p. 179-192.

DOWBOR, L. Indicadores: afinal o que estamos medindo? In: LOUETTE, A. (Org.). Indicadores de Nações: uma Contribuição ao Diálogo da Sustentabilidade: Gestão do Conhecimento/organização, pesquisa, textos e captação de recursos. São Paulo: Willis Harman House, 2007.

FEE. Fundação de Economia e Estatística do Estado do Rio Grande do Sul. Indicadores do potencial poluidor das atividades industriais de transformação e extrativas no Rio Grande do Sul: metodologia. Porto Alegre: FEE, 2014. Disponível em: <http://www.fee. rs.gov.br/wp-content/uploads/2014/02/20140523metodologia_pp_2012.pdf>. Acesso em: 14 jun. 2014.

HAWKEN, P. et al. Capitalismo natural: criando a próxima revolução industrial. São Paulo: Cultrix, 1999.

IBGE. Instituto Brasileiro de Geografia e Estatística. Disponível em: <http://www.ibge.com.br/home>. Acesso em: 14 jun. 2014. 
IPEA. Instituto de Pesquisa Econômica Aplicada. Programa Bolsa Família: uma década de inclusão e cidadania. Sumário executivo. Orgs. Tereza Campello e Marcelo Côrtes Neri. Brasília: IPEA, 2014.

LEFF, E. Racionalidade ambiental: a reapropriação social da natureza. Rio de Janeiro: Civilização Brasileira, 2006.

LEIS, H. R. A modernidade insustentável: as críticas do ambientalismo à sociedade contemporânea. Petrópolis: Vozes; Santa Catarina: UFSC, 1999.

MAWHINNEY, M. Desenvolvimento sustentável: uma introdução ao debate ecológico. São Paulo: Loyola, 2002.

MAY, P. H. Economia ecológica e o desenvolvimento equitativo no Brasil. In: CAVALCANTI, C. (Org.). Desenvolvimento e natureza: estudos para uma sociedade sustentável. São Paulo: Cortez, 1995. p. 235-255.

MAY, P. H.; LUSTOSA, M. C.; VINHA, V. da. Economia do meio ambiente: teoria e prática. Rio de Janeiro: Elsevier, 2003.

MINC, C. Ecologia e cidadania. São Paulo: Moderna, 2005.

MONTIBELLER-FILHO, G. O mito do Desenvolvimento Sustentável: meio ambiente e custos sociais no moderno sistema produtor de mercadorias. Florianópolis: UFSC, 2008.

MUELLER, C. C. Os economistas e as relações entre o sistema econômico e o meio ambiente. Brasília: Universidade de Brasília, 2012.

NORGAARD, R. Valoração ambiental na busca de um futuro sustentável. In: CAVALCANTI, C. (Org.). Meio ambiente, desenvolvimento sustentável e políticas públicas. São Paulo: Cortez, 2001. p. 83-92.

ORTIZ, R. A. Valoração econômica ambiental. In: MAY, P. H.; LUSTOSA, M. C.; VINHA, V. da. Economia do meio ambiente: teoria e prática. Rio de Janeiro: Elsevier, 2003. p. 81-99.

RATTNER, H. Desenvolvimento sustentável - tendências e perspectivas. In: MAGALHÃES, L. E. (Coord.). A questão ambiental. São Paulo: Terragraph, 1994. p. 33-46.

RUSCHEINSKY, A. No conflito das interpretações: o enredo da sustentabilidade. In: 2004. p. 15-33.

(Org.). Sustentabilidade: uma paixão em movimento. Porto Alegre: Sulina,

SACHS, I. Caminhos para o desenvolvimento sustentável. Rio de Janeiro: Garamond, 2002.

. Desenvolvimento: includente, sustentável, sustentado. Rio de Janeiro: Garamond, 2004.

SEKIGUCHI, C.; PIRES, E. L. S. Agenda para uma economia política da sustentabilidade: potencialidades e limites para o seu desenvolvimento no Brasil. In: CAVALCANTI, C. (Org.). Desenvolvimento e natureza: estudos para uma sociedade sustentável. São Paulo: Cortez, 1995. p. 195-207. 
SEMA. Plano da Bacia Hidrográfica Taquari-Antas. Porto Alegre: 2012. Disponível em: <www.taquariantas.com.br>. Acesso em: 14 jun. 2014.

SERAFY, S. E. Contabilidade verde e política econômica. In: CAVALCANTI, C. (Org.). Meio ambiente, desenvolvimento sustentável e políticas públicas. São Paulo: Cortez, 2001. p. 193-214.

SOUZA, R. Entendendo a questão ambiental: temas de economia, política e gestão do meio ambiente. Santa Cruz do Sul: Edunisc, 2000.

TOLMASQUIM, M. T. Economia do meio ambiente: forças e fraquezas.

In: CAVALCANTI, C. (Org.). Desenvolvimento e natureza: estudos para uma sociedade sustentável. São Paulo: Cortez, 1995. p. 323-344.

VEIGA, J. E. Meio ambiente e desenvolvimento. São Paulo: Senac, 2006.

YOUNG, C. E. F. Contabilidade ambiental nacional: fundamentos teóricos e aplicação empírica no Brasil. In: MAY, P. H.; LUSTOSA, M. C.; VINHA, V. da. Economia do meio ambiente: teoria e prática. Rio de Janeiro: Elsevier, 2003. p. 101-132. 